\title{
DEL MEXICO'S MOMENT A NEGOCIAR BAJO PRESIÓN: RELACIONES MÉXICO-EUROPA DURANTE EL SEXENIO DE ENRIQUE PEÑA NIETO, 2012-2018
}

\author{
FROM MEXICO'S MOMENT TO NEGOTIATING UNDER \\ PRESSURE: MEXICO-EUROPE RELATIONS DURING THE \\ SIX-YEAR TERM IN OFFICE OF ENRIQUE PEÑA NIETO,
} 2012-2018

\author{
DU MEXICO'S MOMENT AUX NÉGOCIATIONS \\ SOUS PRESSION: LES RELATIONS \\ MEXIQUE-EUROPE DURANT LA PRÉSIDENCE \\ D’ENRIQUE PEÑA NIETO (2012-2018)
}

\author{
LORENA RuANO GÓMEZ ${ }^{1}$ \\ Centro de Investigación y Docencia Económicas \\ lorena.ruano@cide.edu
}

Resumen: Para entender las relaciones entre México y Europa en el periodo 2012-2018, es necesario tener en cuenta diversos factores contextuales. Si bien hubo cierta continuidad en cuanto a los objetivos de política exterior mexicanos y europeos, los temas de la agenda y el ritmo de las interacciones estuvieron determinados por factores internacionales, regionales y nacionales, ante los cuales fueron más bien reactivos. El artículo identifica tres etapas en las que se dividió el sexenio de Enrique Peña Nieto que, lejos de presentar una trayectoria homogénea, se vio definido por los factores contextuales: el Mexico's Moment, la tormenta y la negociación para modernizar el Acuerdo Global México-Unión Europea.

Palabras clave: política exterior; México; Acuerdo Global México-Unión Europea; Europa, Enrique Peña Nieto; Ayotzinapa; continuidad; Mexico's Moment.

${ }^{1}$ Agradezco el apoyo para la elaboración de este artículo de mis asistentes de investigación, Rosa Elena Rivero Rojas y Ángel Torres Guevara. 
Abstract: To understand the relations between Mexico and Europe over the 2012-2018 period, it is necessary to take a number of contextual factors into account. While there was some continuity in terms of the Mexico and Europe's foreign policy objectives, the issues on the agenda and the pace of interactions were determined by international, regional and domestic factors, to which they were more reactive than active. The article identifies three stages into which the presidency of Enrique Peña Nieto may be divided, which far from presenting a homogeneous course were defined by contextual factors: the Mexico's moment, the storm, and the negotiations to update the Mexico-European Union Global Agreement.

Keywords: foreign policy; Mexico-European Union Global Agreement; Europe; Enrique Peña Nieto; Ayotzinapa; continuity; Mexico's Moment.

\section{Traducción de Gonzalo Celorio Morayta}

RÉSumÉ: Pour mieux saisir les rapports Mexique-Europe dans la période 20122018, il faut tenir compte de plusieurs conditions. Même s'il y a eu une certaine continuité des objectifs internationaux mexicains et européens, les termes de l'agenda et le rythme des échanges ont été déterminés par des éléments mondiaux, régionaux et nationaux, face auxquels les deux acteurs ont réagi. L'article distingue trois étapes dans le gouvernement d'Enrique Peña Nieto, qui loin d'évoquer un parcours homogène ont reflété l'influence de conditions changeantes: le Mexico's moment, la crise et les négociations pour moderniser l'Accord global Union Européenne-Mexique.

Mots clefs: Accord global Union Européenne-Mexique; Enrique Peña

Nieto; Ayotzinapa; continuité; Mexico's Moment.

Traducción de Bernardo Mabire

Fecha de recepción: diciembre de 2018

Fecha de aceptación: febrero de 2019 
E L presente artículo argumenta que para entender las relaciones entre México y Europa en el periodo 2012-2018, no basta con analizar las políticas exteriores de ambas partes, es necesario evaluarlas teniendo en cuenta diversos factores contextuales ante los cuales fueron más bien reactivas. Es cierto que hubo cierta continuidad en los objetivos: atraer inversión a México, promover el comercio y la cooperación y modernizar el Acuerdo Global (AG) entre México y la Unión Europea (UE). ${ }^{2}$ Sin embargo, los temas de la agenda y el ritmo de las interacciones estuvieron determinados por actores y factores internacionales, regionales y nacionales. Con el propósito de desarrollar este argumento, el artículo realiza un recuento histórico basado en fuentes primarias $^{3}$ e identifica tres etapas en las que se dividió la relación de México con Europa en el sexenio de Enrique Peña Nieto (EPN), pues lejos de presentar una trayectoria homogénea, cada una de ellas se vio definida por dichos factores contextuales.

Durante la primera etapa, caracterizada como el Mexico's Moment (2012-2014), el gobierno mexicano logró reemplazar con cierto éxito la imagen violenta del país, que había dejado la administración anterior, por una de eficacia política y promoción de reformas mediante el Pacto por México. Esto entusiasmó a los inversionistas y diplomáticos europeos que veían con buenos ojos la ambición mexicana de convertirse en una potencia emergente constructiva, un "actor con responsabilidad global”. La segunda etapa (2014-2016), en cambio, estuvo marcada por una política exterior defensiva

${ }^{2}$ El nombre completo del Acuerdo Global es Acuerdo de Asociación Económica, Concertación Política y Cooperación entre la Comunidad Europea y sus Estados Miembros y México. Fue firmado en 1997 junto con un Acuerdo Interino de Comercio, el cual fue reemplazado por el Tratado de Libre Comercio Unión Europea-México (Tlcuem), firmado en marzo de 2000. El Acuerdo Global y el TLCuem entraron en vigor en octubre de 2000.

${ }^{3}$ Hemerografía, fuentes oficiales y entrevistas a funcionarios mexicanos y europeos que se mantienen anónimas. 
que buscaba contener los daños ocasionados por los acontecimientos de Ayotzinapa, en septiembre de 2014, y el estallido de varios casos de corrupción meses después, al tiempo que el crecimiento económico decepcionaba y se excluía a México de las negociaciones de libre comercio de la uE con Estados Unidos y Canadá, conocidas en inglés como Transatlantic Trade and Investment Partnership (TTIP) y Comprehensive Economic and Trade Agreement (CETA). La llegada de Trump al poder, en enero de 2017, dio inicio a la tercera etapa, durante la cual Estados Unidos se convirtió en una amenaza para México y Europa, lo que hizo resaltar las coincidencias entre ambos: la defensa del multilateralismo, del comercio basado en reglas y de los acuerdos para enfrentar el cambio climático. Un sentido de urgencia condujo al acercamiento, que se reflejó en la aceleración de las negociaciones para modernizar el Acuerdo Global (AG) entre México y la UE (en vigor desde 2000), las cuales tuvieron como telón de fondo una revisión compleja del Tratado de Libre Comercio de América del Norte (TLCAN) y un apremiante calendario electoral. Se detuvieron en abril de 2018 con un Acuerdo en Principio que falta concluir, firmar y ratificar.

Esta periodización se basa en factores tanto de la política interna mexicana como de la internacional, notablemente, el cambio de gobierno en Estados Unidos. Sin embargo, es preciso señalar que, del lado europeo, se trata de una etapa particularmente complicada: de una crisis a otra, la UE ha ido perdiendo la capacidad de lograr acuerdos internos y, por tanto, se ha acentuado su propensión a la introversión. Al deterioro económico que arrastraba desde 2008, se sumaron el enrarecimiento de las relaciones con Rusia, la llegada masiva de refugiados en 2015, el ascenso de la extrema derecha, el voto en favor del Brexit en el Reino Unido (RU) en 2016, y una crisis política en España que, desde 2015, debilitó al principal motor de la relación de esta región con América Latina.

En el plano birregional, otro escenario en el cual se desenvuelve la relación entre México y Europa, se observa un 
deterioro paulatino de la relación UE-CELAC (Comunidad de Estados Latinoamericanos y Caribeños), proceso cuestionado por los jefes de Estado y de gobierno desde 2013, que culminó con la cancelación de la cumbre prevista para octubre de 2017 en El Salvador, debido a la división entre los países miembros de CELAC en torno a la crisis de Venezuela.

\section{Mexico's Moment}

El comienzo de la administración de Peña Nieto estuvo dominado por una estrategia de comunicación cuyo objetivo era mejorar la imagen de México en el exterior, que se dejara de hablar de violencia y, en su lugar, se percibiera al nuevo gobierno como políticamente eficaz, capaz de llevar a cabo reformas estructurales "de gran calado". Poco antes de asumir el poder, EPN ya planteaba su agenda internacional en un artículo titulado "Mexico's Moment", publicado por la prestigiosa revista británica, The Economist, con la que acordó, además de una portada con la frase The Rise of Mexico, un reportaje especial compuesto por nueve artículos de fondo. ${ }^{4}$ La estrategia tuvo cierto éxito hasta mediados de 2014, sobre todo porque el gobierno logró reformas importantes en el sector energético, de telecomunicaciones y educación, mediante el Pacto por México, lo cual contrastaba con la parálisis en el Congreso que había minado la acción de administraciones anteriores. ${ }^{5}$

Estos cambios despertaron entusiasmo entre los inversionistas y los burócratas europeos que llevaban décadas esperando la apertura de los primeros dos sectores. ${ }^{6}$ Así, en 2013

4 The Economist, 24 de noviembre de 2012.

5 Time, en su edición del 24 de febrero de 2014, le dedicaba la portada a México con el título "Saving Mexico: How Enrique Peña Nieto's sweeping reforms have changed the narrative in his narco-stained nation”. Véase también Leonardo Curzio, Orgullo y prejuicios: reputación e imagen de México, México, unam-Cisan/Porrúa, 2016, pp. 126-130.

${ }^{6}$ Desde 2002, Pascal Lamy, Comisario Europeo de Comercio había criticado el retraso en la apertura del sector energético, las prácticas mo- 
y 2014, la inversión extranjera directa (IED) proveniente de la uE alcanzó picos de cerca de 21 y 11000 millones de dólares, respectivamente, con lo que se convirtió en el primer inversionista en el país (alrededor de 40\%) al superar a EEUU (gráficas 1 y 2). Dado que México se había recuperado relativamente rápido de la crisis de 2008, en comparación con varios países de Europa, se proyectaba incluso como fuente de inversión y ya no sólo como destinatario. ${ }^{7}$ Mientras el príncipe Felipe invitaba a las empresas mexicanas a invertir en España, PEMEX compraba barcos y consideraba establecer una base de distribución en Galicia para sus ventas en Europa. Por su parte, Francia anunciaba inversiones conjuntas en el sector aeroespacial. ${ }^{8}$

En el plano político-diplomático, el lema "México, actor con responsabilidad global", plasmado en el Plan Nacional de Desarrollo, proyectaba una novedosa ambición de ejercer como potencia emergente constructiva, dispuesta a participar en operaciones de mantenimiento de la paz (aprobado internamente en 2013), cuestión en la que Francia había venido insistiendo desde tiempo atrás. ${ }^{9}$ Esta visión positiva de

nopólicas en el sector de telecomunicaciones y las trabas burocráticas en las aduanas mexicanas: "Pide UE apertura a inversión", Reforma, 2 de mayo de 2002; "El comisario de comercio de la ue fortalecerá lazos comerciales en México y Perú", La información, 9 de noviembre de 2012; "El líder del Parlamento Europeo percibe apertura a inversiones en Pemex", investing.com, 12 de febrero de 2013.

7 "Peña Nieto ofrece ayuda a España para salir de la crisis", El Universal, 15 de octubre de 2012; "México invirtió más de 35 mmdd en Europa", Excélsior, 27 de diciembre de 2014; "Cemex compra activos de Holcim en Europa", El Universal, 6 de febrero de 2015.

8 "Beneplácito del presidente electo mexicano al acuerdo con los astilleros españoles", El País, 13 de octubre de 2012; "El príncipe Felipe llama a las empresas mexicanas a invertir en España”, El País, 30 de noviembre de 2012; Juan Diego Quesada, "México y Francia invertirán hasta 500 millones en la industria aeroespacial”, El País, 15 de julio de 2013.

${ }^{9}$ Desde su visita a México en 2009, el presidente francés Nicolás Sarkozy insistió ante el Senado mexicano en que México debía participar con efectivos militares en misiones de mantenimiento de la paz de la onU, Andrea Becerril, "El mundo espera más de México: Sarkozy", La Jornada, 10 de marzo de 2009. 
México contrastaba con el lado europeo, donde el conflicto con Rusia por Ucrania, en 2014, agudizó el ya de por sí enrarecido ambiente que se venía arrastrando desde 2008, debido a la interminable recesión económica y a los jaloneos entre los países de la zona euro. El conflicto fue desencadenado por la firma de un acuerdo de asociación entre Ucrania y la uE al que Rusia se opuso. La subsecuente guerra separatista en el este de Ucrania y la anexión de Crimea por Rusia desataron sanciones de la UE que todavía perduran. Al respecto, México manifestó su preocupación por la situación y se pronunció por la preservación de la integridad territorial de Ucrania, de acuerdo con la postura de la UE. ${ }^{10}$

Así, a pesar de los recortes presupuestales en las cancillerías europeas y de un creciente desinterés por Latinoamérica en su conjunto, se percibía a México (junto con Brasil) como país prioritario en la región, por su tamaño, membresía en foros como el G20 y la oCDE, y posiciones afines en temas de la agenda global como el libre comercio, la lucha contra el cambio climático o la defensa de los derechos humanos. México era, además, el país de América Latina con el cual la UE tenía la relación más institucionalizada, con el AG desde 2000 (como Chile) y con una Asociación Estratégica desde 2007 (como Brasil).

El objetivo mexicano hacia el exterior consistió, según los informes de labores de la cancillería, en "ampliar y fortalecer la presencia de México en mundo”. En el caso de Europa, esto se tradujo en promover los vínculos bilaterales con visitas de alto nivel más allá de los socios que tradicionalmente habían dominado la relación, como España y Bruselas (UE), para acercarse más a las otras potencias como Francia, Alemania, RU e Italia, y otros países con los que se tenían relaciones menos desarrolladas como Suecia, Portugal, Rusia, Turquía o

10 "México lamenta actos de violencia y muertes en Ucrania”, El Universal, 19 de febrero de 2014. Secretaría de Relaciones Exteriores, SRE, "México manifiesta su profunda preocupación por el deterioro de la situación en Ucrania”, Comunicado de prensa, 4 de marzo de 2014. 
Macedonia. ${ }^{11}$ Si bien antes de tomar posesión, EPN visitó España y Alemania, países prioritarios en la región, ${ }^{12}$ en contraste con sexenios anteriores, la primera visita presidencial a Europa no incluyó parada en Madrid, sino que fue a Roma para asistir a la ceremonia de inicio del pontificado del papa Francisco. Su segunda visita fue al RU para asistir al G20 en junio de 2013. En ese año, las visitas europeas de alto nivel fueron del primer ministro de Suecia, Frederik Reinfeldt, del príncipe Federico de Dinamarca, del presidente del Parlamento Europeo (PE), Martin Schulz, y del primer ministro portugués, Pedro Passos Coelho.

EPN visitó España hasta junio de 2014, después de pasar por Portugal, acompañado de un grupo de empresarios. En esa ocasión, manifestantes le gritaron "asesino" por la matanza de Atenco, después de lo cual volvió solamente en 2018. Por su parte, el presidente del gobierno español, Mariano Rajoy, tampoco vino a México en visita bilateral durante el sexenio. Esta relativa escasez de visitas de alto nivel con respecto al pasado se debió también a que España, golpeada por la crisis económica y política (y sin gobierno durante casi un año en 2016), dejó gran parte de sus relaciones con América Latina en manos de sus empresarios, además de que fue perdiendo influencia dentro de una uE cada vez más diversa tras sucesivas ampliaciones. ${ }^{13}$ De alguna forma, el relativo abandono de España en la estrategia hacia Europa se compensó con el nombramiento en la embajada de Madrid de Roberta Lajous, experimentada diplomática con peso político, puesto en el que duró desde octubre de 2013 hasta el final del sexenio.

${ }^{11}$ Secretaría de Relaciones Exteriores, SRE, $1^{\text {er }}$ Informe de labores, $2012-$ 2013, México, 2014, pp. 59-67.

12 Rosa Elvira Vargas, "Peña Nieto llegó ayer a Alemania; se reúne hoy con Merkel", La Jornada, 11 de octubre de 2012; "Recibe rey Juan Carlos a Peña Nieto", El Universal, 15 de octubre de 2012.

${ }^{13}$ Miguel González, "Francia e Italia toman la delantera a España en América Latina", El Pais, 9 de febrero de 2016. 
Durante los primeros dos años, la prioridad fue reconstruir la relación con Francia tras el asunto de Florence Cassez, quien fue liberada en enero de 2013. Vino entonces la reactivación del Consejo Estratégico Franco-Mexicano, cuya actividad había quedado congelada. Estos esfuerzos culminaron en 2014 con una importante exposición sobre los mayas en el Quai de Branly y con la visita a México del presidente François Hollande, durante la cual se conmemoró también la histórica visita del general De Gaulle, cincuenta años atrás. ${ }^{14}$

Con Alemania, que tras la crisis se había erigido en la indiscutible potencia regional, se enviaron dos señales de interés para fortalecer la relación. Por un lado, se nombró como embajadora a Patricia Espinosa, excanciller y, por el otro, en 2013 se abrió una oficina de la Secretaría de Turismo en aquel país para preparar la participación de México como nación invitada de la Feria Internacional de Turismo de Berlín de 2014. Sin embargo, el esfuerzo de promoción de "la marca México" se vio minado por la advertencia del Ministerio de Asuntos Exteriores alemán de evitar viajar a los estados de Michoacán, Jalisco, Colima y Guerrero, debido a la violencia. ${ }^{15}$ Esto simbolizó la dinámica por venir.

Con el RU se buscó también potenciar las relaciones, tras el nombramiento político en la embajada de Londres de Diego Gómez Pickering, diplomático inexperto, pero próximo al presidente EPN. Se notó un acercamiento con la visita del viceprimer ministro de aquella nación, Nick Clegg, y la del príncipe Carlos y su esposa Camilla (2014), ocasión en la que se anunció que la celebración del año dual México-Ru sería en $2015 .{ }^{16}$

${ }^{14}$ Luis Pablo Beauregard, "Francia y México buscan el deshielo de sus relaciones tras el «affaire» Cassez”, El País, 9 de abril de 2014.

${ }^{15}$ Enrique Müller, "La violencia empaña brillo de México en la Feria Internacional de Turismo de Berlín”, El País, 25 de febrero de 2014.

${ }^{16}$ Secretaría de Relaciones Exteriores, SRE, 3er Informe de labores, 2015, México, p. 71. 
A pesar de los avances en la estrategia de posicionamiento, imagen y diversificación ante los europeos, México quedó fuera de las negociaciones comerciales de última generación que la ue llevaba a cabo con sus socios de América del Norte. Con Canadá habían iniciado desde 2009 y, con Estados Unidos, en julio de 2013 para establecer el TTIP. Ante esta perspectiva, México insistió en actualizar el AG y en junio de 2013 obtuvo el compromiso de la uE para ello, pero la negociación tardó tres años en arrancar. La elaboración del mandato negociador en la uE tardó hasta finales de 2015, dado que estaba sujeto a lo que se acordara con Estados Unidos y Canadá, y a la elaboración de un nuevo documento de política comercial que la Comisión Europea (CE) dio a conocer en 2015.17

En el plano birregional, la relación entre la UE y América Latina entró en una fase extraña. Por un lado, en 2011 ésta parecía institucionalizarse tras la creación de la CELAC a instancias de México, con el propósito de coordinar la interlocución con actores extrarregionales, en especial con la uE. Por otro lado, la cELAC se fue revelando incapaz de salvar las diferencias derivadas de la creciente polarización en la región. La cumbre de Santiago UE-CELAC, prevista para 2012, tuvo que posponerse a 2013, y cuando tuvo lugar, fue antes de que lo hiciera la propia cELAC, con lo cual no cumplió su propósito de coordinación. Los anuncios sustanciales emanados de esa reunión se referían a los acuerdos de la uE con países o grupos de países (Colombia, Perú, Centroamérica, México), mientras el contenido birregional como tal languidecía. Esto se debió, entre otras razones, a la reforma de la política europea de ayuda al desarrollo, que anunciaba la "graduación" de los países de renta media y, por tanto, el fin de la ayuda bilateral a la mayoría de los países latinoamericanos.

${ }^{17}$ European Commission (Ec), Trade for All-Towards a more responsible trade and investment policy, Bruselas, 2015. 
LA TORMENTA (SEPTIEMbRE DE 2014-NOVIEMbRE DE 2016)

Entre finales de 2014 y de 2016, la dinámica con Europa cambió notablemente debido a fuertes sacudidas en los entornos mexicano y europeo. En México, el deterioro de la imagen fue abrupto tras los sucesos de Ayotzinapa en septiembre de 2014, después de los cuales no se pudieron disimular ya ni el alarmante aumento de la violencia, ni los aparatosos escándalos de corrupción que le siguieron. ${ }^{18}$ El Mexico's Moment dio paso a una política exterior reactiva, orientada a la contención de daños, y coincidió con la sustitución del canciller José Antonio Meade por Claudia Ruiz Massieu. En lo económico, la caída de los precios del petróleo, en 2014, impuso una política de austeridad en el gasto del gobierno que frenó la economía. A esto se sumó el retraso en la implementación de las reformas estructurales, con el efecto de reducir la llegada de los capitales europeos que se había esperado. Tras los picos de 2013 y 2014, la proporción de IED proveniente de Europa volvió a sus niveles históricos, de alrededor de $30 \%$ del total (gráfica 1).

En Europa, tres elementos se sumaron para profundizar el sentimiento de crisis múltiple, acaparando la atención de los países de la uE. Primero, en 2015, la llegada masiva de inmigrantes, a quienes en un principio, la canciller alemana Angela Merkel quiso recibir con puertas abiertas, generó rechazo entre varios socios europeos e incluso entre fuerzas políticas alemanas. En consecuencia, varios países reintrodujeron cruces fronterizos dentro del espacio Schengen, como Suecia, Dinamarca y Austria, mientras que Hungría y Polonia se opusieron a la propuesta de la cE de establecer cuotas para repartir a los inmigrantes. Entre tanto, Grecia, Italia y España se veían desbordadas para procesar las solicitudes de asilo, al ser los países de entrada a la uE por el

18 Pedro Villa y Caña, "Regresan protestas a ciudades de América y Europa”, El Universal, 23 de octubre de 2014. 
Mediterráneo. ${ }^{19}$ Segundo, en junio de 2016 el gobierno británico de David Cameron, acechado por un fuerte euroescepticismo en su propio partido, organizó un referéndum acerca de la permanencia de su país en la uE. La votación resultó en favor del Brexit y, lejos de zanjar la cuestión, sumió al RU en la crisis política interna más grave que ha visto desde 1945. En Bruselas y las capitales nacionales se hablaba de desintegración. Tercero, diversos atentados en París (enero y noviembre de 2015), Bruselas (marzo de 2016) y Berlín (diciembre de 2016) abonaron al rechazo de los inmigrantes, generando un ambiente de xenofobia, islamofobia y nacionalismo en casi toda Europa, sin precedentes desde la década de 1930 .

Los efectos directos para México de estos hechos fueron, en el corto plazo, relativamente limitados. La ola migratoria resultó en un endurecimiento de los requisitos migratorios pero, dado que la migración latinoamericana hacia Europa es reducida, se complicó sobre todo con la llegada y permanencia de los estudiantes mexicanos en el RU, que hasta entonces había sido el segundo destino más importante para cursar posgrados. A inicios de 2016 también se estableció que, arrancando 2020, habría que hacer un registro previo en línea para visitar el espacio Schengen, aunque no se requiera visa. ${ }^{20}$ Por su parte, el shock financiero internacional tras el referéndum del Brexit se hizo sentir en la economía mexicana por medio de volatilidad en la bolsa y en el valor del peso, que coincidieron con otro recorte del gasto gubernamental.

En cuanto a la estrategia de México hacia la región, en este periodo se observa cierta continuidad: el objetivo seguía

${ }^{19}$ Günther Maihold, "Migración, control de fronteras y acuerdos migratorios con terceros países”, Revista Mexicana de Política Exterior, (2018), 112, pp. 161-183.

20 “Así funcionará el nuevo trámite para ingresar a los países de Europa del espacio Schengen", BBC News Mundo, https://www.bbc.com/ mundo/noticias-america-latina-38015758 (consulta del 27 de noviembre de 2018). 
siendo la promoción económica y de las reformas estructurales. Por tanto, se dio seguimiento a las iniciativas para fortalecer las relaciones con Francia, Alemania y el RU, y se mantuvo la "ampliación" de relaciones hacia otros países como Finlandia, Turquía (por el grupo miктA -México, Indonesia, Corea, Turquía y Australia-) e Italia, con visitas presidenciales en 2015. ${ }^{21}$ Sin embargo, la estrategia ahora contrastaba con un contexto en el cual la imagen del país se había deteriorado. Así, en 2016, que fue quizá el año más complicado aun si vinieron a México el primer ministro de Finlandia, Jüha Sipilä, el de Italia, Matteo Renzi, y el papa Francisco, ${ }^{22}$ las visitas de EPN a Dinamarca y Alemania se vieron empañadas por señalamientos duros por parte de sus homólogos. ${ }^{23}$

Con el RU, el presidente realizó una visita de Estado en 2015 como parte de las actividades del año dual, con el objetivo de seguir promoviendo el intercambio económico y firmar varios convenios de cooperación en educación, energía, salud y turismo. A final de ese año, el país europeo fue el invitado de honor en la Feria Internacional del Libro de Guadalajara. Sin embargo, la prensa británica no dejó de hacerse eco de la situación de derechos humanos en México, y el primer ministro Cameron tocó el tema durante la visita de EPN. ${ }^{24}$ Por otra parte, el embajador Gómez Pickering se retiró en marzo de 2016 y no fue reemplazado sino hasta marzo de 2017, por Julián Ventura, con lo cual México estuvo un año sin embajador en uno de los países más importantes de Europa y en un momento crucial, el referéndum sobre el Brexit.

${ }^{21}$ Secretaría de Relaciones Exteriores, SRE, $3^{\text {er }}$ Informe de labores 2015, pp. 68-69.

${ }^{22}$ Secretaría de Relaciones Exteriores, SRE, $4^{\circ}$ Informe de labores 2016, pp. 81-86.

23 "Diplomacia pendenciera y vilipendiada", Proceso, 19 de abril de 2016.

${ }^{24}$ Pedro Villa y Caña, "Movilización por los 43 tiene eco internacional”, El Universal, 27 de febrero de 2015; "Mexico human rights: Cameron to raise issue with Pena Nieto", 4 de marzo de 2015, https://www.bbc. com/news/uk-31723447 (consulta del 27 de noviembre de 2018). 
Durante esos meses, en un encuentro del G20, EPN habló con la primera ministra Theresa May acerca de un posible acuerdo de libre comercio, una vez que su nación concretara su salida de la UE. ${ }^{25}$

A Francia, el presidente Peña hizo una visita de Estado acompañado de un nutrido séquito de más de 400 personas, para asistir como invitado especial a la ceremonia del 14 de julio en 2015. Este viaje tampoco estuvo exento de protestas por parte de activistas de derechos humanos y de exhortos para que el presidente Hollande criticara la situación en México. ${ }^{26}$ El nombramiento de Juan Manuel Gómez Robledo, exsubsecretario, como embajador en París, fue otra medida que contribuyó a elevar el perfil de la relación bilateral, por su peso político y experiencia. En 2016, se celebró el año de México en Francia y, como parte de estas actividades, en octubre se inauguró una exitosa exposición de arte mexicano en el Grand Palais de París.

Con Alemania, en 2015, se estableció una comisión binacional para preparar el año dual que tuvo lugar entre 20162017 con un número importante de actividades conjuntas en ambos países, entre las cuales resaltó una gran exposición sobre los mayas en Berlín. A pesar de esto, su visita oficial a esa ciudad, prevista para echar a andar varios actos culturales, turísticos y económicos, en abril de 2016, coincidió con las críticas del gobierno mexicano hacia el trabajo del Grupo Interdisciplinario de Expertos Independientes (GIEI) de la Comisión Interamericana de Derechos Humanos (CIDH) y la negativa para renovar su mandato seis meses más. Esto provocó llamadas de atención por parte del presidente alemán, Joachim Gauck, y de la canciller Merkel. ${ }^{27}$

25 "Reino Unido abre la puerta a México a un TLC tras el Brexit", El Financiero, 5 de septiembre de 2016.

26 "Activistas franceses protestan en el Consejo de París contra la visita de Peña Nieto en Francia”, Sin embargo, 2 de julio de 2015, https: / /www.sin embargo.mx/02-07-2015/1400095 (consulta del 27 de noviembre de 2018).

27 "Diplomacia pendenciera y vilipendiada", Proceso, 19 de abril de 2016. 
Con España, este periodo fue complicado debido, por un lado, a las crisis políticas en ese país, que minaron su capacidad de proyección hacia el exterior. Tras los escándalos de corrupción que forzaron la sucesión monárquica, España pasó más de diez meses (entre el 21 de diciembre de 2015 y el 28 de octubre de 2016) sin gobierno, una situación sin precedentes en su historia democrática. Fueron, por tanto, los nuevos reyes, Felipe VI y Letizia, quienes se ocuparon de la relación con México, al visitarlo en una de sus primeras salidas al exterior en junio de 2015, y poniendo énfasis en los temas económicos y en la cooperación cultural entre la UNAM y el Instituto Cervantes -que resultó en la creación de un Sistema de Evaluación Internacional del Español (sIELE)-. ${ }^{28}$ Por otro lado, los problemas mexicanos de corrupción saltaron a la agenda bilateral en febrero de 2016, cuando fue apresado en Madrid el exgobernador Humberto Moreira y la embajada tuvo que movilizarse para liberarlo. ${ }^{29}$ Otra situación incómoda se generó en octubre de ese mismo año, con el nombramiento como cónsul en Barcelona de Fidel Herrera, exgobernador de Veracruz, lo cual dio una muy mala impresión y suscitó protestas de organizaciones locales, hasta que abandonó el cargo en enero de 2017. ${ }^{30}$

El debilitamiento de las credenciales democráticas debido al deterioro del Estado de derecho provocó que las críticas europeas (que habían sido una constante en las relaciones México-Europa desde la presidencia de Vicente Fox) volvieran a ser duras y recurrentes tras un par de años de relativa tregua. El manejo de la investigación del gobierno por la desaparición de los 43 estudiantes en Iguala fue muy criticado

28 Miguel González, "Los Reyes viajan a México para su segunda visita de Estado", El País, 27 de julio de 2015.

${ }^{29}$ José María Irujo, "Misión: salvar en Madrid a Humberto Moreira”, El País, 22 de febrero de 2016.

30 Para que su nombramiento no tuviera que pasar por el Senado mexicano, se modificó el estatus del consulado en Barcelona. "Fidel Herrera renuncia a consulado de México en Barcelona”, El Universal, 22 de enero de 2017. 
por la prensa y las organizaciones no gubernamentales (ONG) desde un inicio, pero lo que desató mayor malestar fue la actitud de descalificación hacia el GIEI, la Comisión de Derechos Humanos de la onU, en 2015, y el reporte sobre derechos humanos del Departamento de Estado estadounidense. Las ONG europeas fueron duras, ${ }^{31}$ mientras que el PE y el Servicio Europeo de Acción Externa (SEAE) se pronunciaron de manera más diplomática, expresando por un lado las críticas de manera abierta y, por otro, resaltando su apoyo y confianza en el gobierno de México para resolver la situación. ${ }^{32}$

Durante su viaje a México en mayo de 2016, la alta representante de la uE para Asuntos Exteriores y de Seguridad, vicepresidenta de la CE, Federica Mogherini, no sólo vino a anunciar el inicio de las negociaciones para actualizar el AG, también inauguró la Segunda Ronda del Diálogo de Alto Nivel sobre Seguridad y Justicia México-ue, la cual tocó temas de delincuencia organizada, Estado de derecho y derechos humanos. ${ }^{33}$ Se reunió con el secretario de Gobernación, Miguel Ángel Osorio Chong, la procuradora general, Arely Gómez, después de un encuentro con miembros de la sociedad civil, ante quienes expresó la preocupación en la UE y los Estados miembros por la situación en México y explicó los tres instrumentos para ayudar o presionar a México en la materia: 1. Condicionar las negociaciones para la modernización

31 "Mexico: Joint statement of NGOs in the European Union (EU) on the publication of the final GIEI Report", Coordinación Alemana por los Derechos Humanos en México, 17 de mayo de 2016, https:/ / esp.mexikokoordination.de/40-tagung-2012/125-mexico-joint-statement-of-ngos-inthe-european-union-eu-on-the-publication-of-the-final-giei-report.html (consulta del 28 de noviembre de 2018).

${ }^{32} \mathrm{PE}$, "Declaración de la portavoz sobre el informe final del GIEI acerca de la investigación sobre la desaparición de los 43 estudiantes en Iguala (México)", 2014/2905 (RSP); SEAE, Comunicado de prensa 161107_10, Bruselas, 29 de abril de 2016.

${ }^{33}$ Delegación de la Unión Europea en México, "Alta Representante de la UE para Asuntos Exteriores y de Seguridad/Vicepresidenta, Federica Mogherini visita México el 24 y 25 de mayo", Comunicado de prensa, 23 de mayo de 2016. 
del AG a un diálogo más profundo sobre estos asuntos en todos los niveles; 2. Ejercer presión política por medio del naming and shaming; 3. Ofrecer cooperación técnica con recursos dirigidos a capacitación de los ministerios públicos, forenses, investigadores, sistemas de justicia, entre otros.

En efecto, la renegociación del AG, que México había planteado desde 2013, fue lenta en este periodo. En la VII Cumbre ue-México en junio de 2015, simplemente se reafirmó la intención de lanzar el proceso ese año. ${ }^{34} \mathrm{El}$ retraso se debió, además del asunto de los derechos humanos, a otras dos razones. Primero, la UE le dio prioridad a la negociación del CeTa (que concluyó en 2014 y se firmó en octubre de 2016) y del TTIP, que se estancó en 2016, dejando la vía libre para México. Segundo, preparar el mandato negociador dentro de la propia uE es un ejercicio largo, una negociación multilateral muy técnica y compleja. La CE no presentó su estudio de impacto sino hasta diciembre de $2015,{ }^{35}$ momento a partir del cual dio inicio un proceso de consultas con los Estados miembros y el PE, para definir el mandato en cada uno de los capítulos, lo cual fue aprobado por el Consejo de la UE a finales de mayo de 2016. De este modo, la primera ronda de negociaciones se llevó a cabo en Bruselas entre el 13 y 14 de junio de 2016. ${ }^{36}$ Aun entonces, las negociaciones siguieron moviéndose lentas hasta noviembre de ese año, cuando la elección de Donald Trump a la presidencia de Estados Unidos desató todas las alarmas.

34 VII EU-Mexico Summit, Joint Statement, Bruselas, 12 de junio de $2015, \S 3$.

${ }^{35}$ EC, Commission Staff Working Document. Impact Assessment accompanying the document Recommendation for a Council Decision authorising the European Commission and the High Representative of the Union for Foreign Affairs and Security Policy to open negotiations and to negotiate with Mexico a modernised Global Agreement, SWD (2015) 289 final, Bruselas, 16 de diciembre de 2015.

36 Francisco del Río y Raúl Saavedra Cinta, "Modernización de los capítulos de diálogo político y de cooperación del Acuerdo Global México-Unión Europea”, Revista Mexicana de Política Exterior, 112 (2018), p. 41. 
En el plano birregional, la cumbre UE-CELAC de 2015, en Bruselas, fue un tanto desangelada y dio la impresión de un proceso agotado, a tal grado que los jefes de Estado y de gobierno encomendaron a sus ministros de asuntos exteriores hacer una evaluación crítica y plantear recomendaciones para darle un contenido más real y concreto. ${ }^{37}$ Esta preocupación venía de tiempo atrás, pues en la cumbre de Madrid de 2010 se había presentado un "plan de acción” para concentrar los esfuerzos en cinco temas, pero cada cumbre subsiguiente añadió temas, hasta llegar a diez en 2015. Los ministros se reunieron en República Dominicana en 2016 y pusieron sobre la mesa varios temas a discusión, entre ellos, la reforma de los programas de ayuda al desarrollo de la UE que desaparecieron de manera bilateral para muchos países de América Latina, sustrayendo una parte importante de la base concreta de la relación. ${ }^{38}$ Por otra parte, la crisis política y económica de Brasil dejó a Sudamérica sin un liderazgo que había sido esencial años atrás, y a México, relativamente mejor posicionado como socio clave de la uE en la región. De hecho, el resultado más importante de la cumbre fue el anuncio de la renegociación del Ag México-Ue.

Bajo presión: la renegociación del AGuerdo Global México-Unión Europea (nOviembre 2016-NOVIEMBRE 2018)

Durante este periodo tuvo lugar un reacercamiento importante entre México y Europa, que se plasmó en un esfuerzo de

${ }^{37}$ EU-CELAC Brussels Summit 2015, EU-CELAC Action Plan, Bruselas, 10-11 de junio de 2015.

38 Political Declaration of EU-CELAC Heads of State and Government, Bruselas, 10-11 de junio de 2015, $\$ 7$; Los resultados de ese ejercicio quedaron plasmados en el documento CELAC-EU, Assessment of Programmes and Actions, Santo Domingo, 2016, http://www.consilium.europa.eu/media/24 235/read-the-assessment-of-programmes-and-actions.pdf (consulta del 28 de noviembre de 2018). 
ambas partes por avanzar en la negociación para actualizar el AG. La presión vino, sobre todo, del ámbito internacional, con la elección de Donald Trump en noviembre de 2016, lo cual convirtió a Estados Unidos en una amenaza común que visibilizó las coincidencias entre México y la UE, y la necesidad de coaligarse para defender el libre comercio basado en reglas y la lucha contra el cambio climático, entre otros.

Para México, que se había convertido en la "piñata favorita" de Trump desde la campaña, los efectos en la cotización del peso y la bolsa se empezaron a sentir incluso antes de la elección, tras la cual la situación se tornó sumamente delicada, pues el nuevo presidente amenazaba con denunciar el TLCAN (que se convirtió en una complicada renegociación) y construir un muro en la frontera. Este choque externo se sumaba al deterioro imparable en la legitimidad del gobierno mexicano debido a la creciente inseguridad, corrupción y a la perspectiva de las elecciones de julio de 2018. Este último factor suponía mayor premura para concretar un acuerdo con la uE que se convirtiera en un amarre externo de las reformas estructurales logradas a principios del sexenio, además de contribuir a la diversificación comercial y financiera, que se hacía más urgente que nunca. ${ }^{39}$ Con la llegada de Luis Videgaray, hombre cercano al presidente, a la SRE a principios de enero 2017, la política exterior se dotó de nueva fuerza y recursos para enfrentar la situación. El canciller se reunió en dos ocasiones con los diplomáticos mexicanos acreditados en Europa, a quienes pidió redoblar los esfuerzos para fortalecer los vínculos con los países de la región, especialmente los comerciales y de inversión. ${ }^{40}$

Para Europa, que por fin comenzaba a recuperarse de la gran recesión, la llegada de Trump representó un cuestiona-

${ }^{39}$ En enero de 2017, México emprendió una estrategia de diversificación comercial, al continuar con la negociación el TPP, a pesar de la salida de Estados Unidos, al reforzar los lazos con la Alianza del Pacífico y explorar una profundización con Argentina y Brasil.

${ }^{40}$ Ariadna García, "Videgaray pide a diplomáticos impulsar a México en Europa”, El Universal, 19 de febrero de 2017. 
miento profundo de la comunidad transatlántica sobre la cual había construido, desde 1945, no sólo su seguridad, sino también su prosperidad. Que su principal aliado militar, político y económico cuestionara a la Organización del Tratado del Atlántico Norte (OTAN), dijera que Bruselas era un hell-hole, aplaudiera el Brexit, amenazara con una guerra comercial y se saliera del Acuerdo de París contra el Cambio Climático trajo un desconcierto mayúsculo. La reacción de Bruselas, París y Berlín fue reforzar la cooperación europea en temas de seguridad y acelerar la negociación de acuerdos de libre comercio con diversos socios, incluyendo el MERCoSur, México, Japón, Singapur, otros países de Asia, Australia y Nueva Zelanda. Desde enero de 2017, el presidente del Consejo Europeo, Donald Tusk, dijo a los Estados miembros de la uE que había que aprovechar el cambio en la estrategia comercial de Estados Unidos para reforzar los lazos con países afines interesados. ${ }^{41}$ Meses después, la canciller Merkel, a quien algunos analistas veían como la "nueva líder del mundo libre", advertía que los europeos "debían tomar su destino en sus propias manos", que ya no podían seguir dependiendo de los aliados después de Trump y el Brexit. ${ }^{42}$ La elección de Emmanuel Macron a la presidencia francesa en junio de ese año, frente a la ultraderechista Marine Le Pen, trajo un respiro y un refuerzo al discurso europeísta. A pesar de esta victoria y del avance en la cooperación de varios frentes en Bruselas, 2017 y 2018 vieron llegar a los parlamentos de todo

41 "'United we stand, divided we fall', Letter by President Donald Tusk to the $27 \mathrm{EU}$ heads of state or government on the future of the EU before the Malta Summit”, 31 de enero de 2017, www.consilium.europa.eu/en/ press/press-releases/2017/01/31-tusk-letter-future-europe/ (consulta del 30 de noviembre de 2018).

42 "Angela Merkel: The new leader of the Free World", Politico, enero de 2017, www.politico.com/interactives/2017/politico50/angela-merkel (consulta del 3 de diciembre de 2018); "Merkel: Europe «can no longer rely on allies» after Trump and Brexit”, BBC News, 28 de mayo de 2017, https://www.bbc.com/news/world-europe-40078183 (consulta del 30 de noviembre de 2018). 
el continente a partidos de ultraderecha y antisistema (Alemania, Países Bajos, Escandinavia) e, incluso, a varios gobiernos, como en Austria e Italia, que se sumaron al antieuropeísmo de los gobiernos "iliberales" de Polonia y Hungría. Este ascenso de la ultraderecha y del nacionalismo, la fragmentación de los sistemas de partidos y la consiguiente dificultad para formar gobiernos no deja de ser preocupante y de dificultar la toma de decisiones en la UE.

Fue en este contexto tan enrarecido en el que, a partir de enero de 2017, se vio un discreto apoyo de la uE hacia México con la aceleración de la renegociación del AG y una declaración del PE. ${ }^{43}$ En mayo de 2017, la comisaria europea de comercio, Cecilia Malmström, visitó México para enviar una clara señal al mundo sobre la importancia de fortalecer -en lugar de debilitar- las reglas del comercio internacional. ${ }^{44} \mathrm{El}$ objetivo concreto de la renegociación era "modernizar" o "actualizar" el AG, en el sentido de incorporar los temas de la "nueva agenda comercial", como compras de gobierno, comercio digital, propiedad intelectual, y vincular al comercio con desarrollo sustentable, temas de género y corrupción. También se buscaba mayor apertura en los "viejos" temas, como barreras no arancelarias, agilización de aduanas, reducción de las reglas de origen o ampliación de la lista de productos agrícolas sin barreras. En inversiones, se reforzó el sistema de solución de controversias, mediante un tribunal permanente para reemplazar los paneles ad hoc. En las partes de diálogo político y de cooperación, era necesario tomar en cuenta la creación de la Agencia Mexicana de Cooperación Internacional para el Desarrollo (Amexcid), en

${ }^{43}$ El apoyo fue "discreto" porque la cancillería mexicana así lo solicitó a las autoridades europeas. Entrevista con alto funcionario del SEAE, Bruselas, 7 de febrero de 2017. Inder Bugarin,"Eurodiputados apoyan a México contra Trump”, El Universal, 27 de enero de 2017.

44 "EU Trade Commissioner in Mexico: «Trade deal possible by year's end»”, México, European Commission, 8 de mayo de 2017, http:/ / trade. ec.europa.eu/doclib/press/index.cfm?id=1659 (consulta del 30 de noviembre del 2018). 
2011, y la reforma de la política de ayuda al desarrollo de la uE desde 2013, así como incorporar al tratado ciertas prácticas de diálogo como las cumbres ue-México y los diálogos interparlamentarios (cuadro 2). ${ }^{45}$ Las negociaciones avanzaban a contrarreloj y al mismo tiempo que aquellas para establecer el nuevo Tratado México-Estados Unidos-Canadá (T-MEC), bajo enorme presión para México. Así fue como se anunció el 21 de abril de 2018 un "acuerdo en principio" que marcaba el fin del grueso de la negociación, aunque cabe aclarar que no ha concluido del todo y que más bien se definieron los principios para zanjar las cuestiones pendientes. ${ }^{46} \mathrm{Al}$ terminar la gestión de EPN, el tratado todavía no se había terminado de negociar, de modo que toca a la administración de Andrés Manuel López Obrador concluirlo, firmarlo y ratificarlo.

En el plano bilateral, durante este periodo fue notorio el apoyo de Alemania frente a la hostilidad que emanaba de Washington. La canciller Merkel visitó México en junio de 2017, como parte de las actividades del año dual, y criticó abiertamente la idea del muro en la frontera, así como el proteccionismo comercial de Estados Unidos. El apoyo alemán fue fundamental para avanzar en las negociaciones con la UE. Por su parte, EPN viajó a Hamburgo para una reunión del G20 en julio de 2017, e inauguró la Feria de Hannover sobre economía 4.0 en la que México fue país invitado durante su última visita a Europa en abril 2018. ${ }^{47} \mathrm{~A}$ pesar de

${ }^{45}$ Para más detalles sobre la renegociación del acuerdo, véase, Del Río y Saavedra, Revista Mexicana de Política Exterior, 112 ,(2018); Carlos de Icaza "México y Europa: una historia de amistad, solidaridad y cooperación”, Revista Mexicana de Política Exterior, 112 ,(2018), pp. 17-32; Lorena Ruano, "The «Modernisation» of the Global Agreement between Mexico and the EU" en Antonella Mori, (ed.), EU and Latin America and the Caribbean: A Stronger Partnership?, Roma, ISPI, 2018, pp. 47-66.

46 "New EU-Mexico Agreement: The Agreement in Principle", Bruselas, Unión Europea, 23 de abril de 2018, http://trade.ec.europa.eu/doclib /docs/2018/april/tradoc_156791.pdf (consulta del 20 de junio de 2018).

${ }^{47}$ Rogelio Granguillhome Morfín y Víctor Manuel Jiménez Segovia, "Las relaciones con Alemania y cómo fortalecer la presencia de México 
este apoyo, Merkel no dejó de mencionar en sus encuentros la preocupación alemana por los derechos humanos en México. ${ }^{48}$ La desaparición de dos ciclistas europeos en Chiapas, uno de ellos alemán (el otro, polaco), en mayo de 2018, nuevamente dejaba en evidencia la grave situación en materia de seguridad, ${ }^{49}$ de la cual el gobierno alemán alertó a sus viajeros en dos ocasiones durante estos años. ${ }^{50}$

Con Francia hubo también actividad diplomática de alto nivel durante 2017. Primero, el canciller Videgaray fue a París en marzo y, luego, el presidente Peña, en julio, para almorzar con el recién electo Emmanuel Macron. ${ }^{51}$ En noviembre vino a México el ministro de Asuntos Exteriores, Jean-Yves Le Drian, para continuar con la puesta en marcha de más de cien convenios de cooperación cultural, científica, de salud, seguridad y desarrollo sustentable, de acuerdo con una hoja de ruta desarrollada desde la visita de Hollande en 2014, cuyo objetivo fue establecer una asociación estratégica y obtener el respaldo de Francia en la negociación con la UE. ${ }^{52}$ En diciembre, EPN fue nuevamente a París para asistir a la cumbre One Planet, en la cual se evaluó el compromiso de los países con la lucha contra el cambio climático, y volvió a reunirse con el

en el mundo de hoy", Revista Mexicana de Política Exterior, 112 (2018), pp. 109-128.

48 "Angela Merkel condemns «putting up walls» during Mexico visit" y "Germany's Merkel talks trade and human rights in Mexico", Daily Mail, 9 de junio de 2017.

49 Elena Reina, "El trágico final de dos ciclistas europeos asesinados en Chiapas”, El País, 12 de mayo de 2018.

${ }^{50}$ A principios de 2017, Gran Bretaña, Francia y Alemania emitieron alertas de seguridad por las manifestaciones en contra del aumento del precio de la gasolina, y en febrero de 2018, de cara a las elecciones de julio de 2018. Inder Bugarin, "Europa, inquieta por protestas", El Universal, 10 de enero de 2017; "Germany issues travel advisory for Mexico due to expected violence in the run up to the elections", El Universal [en inglés], 27 de febrero de 2018.

51 "Peña Nieto parte a Europa para gira de trabajo", Notimex, 5 de julio de 2017.

52 "France-Mexique: entre Paris et Mexico, un partenariat stratégique sur les rails”, Le Moci, 6 de noviembre de 2017. 
presidente Macron. ${ }^{53}$ Ese mismo año, Francia fue el invitado especial en el Festival Internacional Cervantino en 2017.

Con España, en cambio, las relaciones continuaron por un camino de claroscuros. A principios de 2017, frente a los embates de Trump contra México, el portavoz del gobierno español se limitó a llamar al diálogo a ambas partes y su tibieza fue objeto de fuertes críticas de la oposición socialista que exigía mayor solidaridad. ${ }^{54}$ Durante la segunda mitad de ese año, la crisis por el independentismo catalán volvió a absorber al gobierno español, mientras que el uso de la fuerza desplegado para reprimir a los organizadores del referéndum del $1^{\circ}$ de octubre minaba la imagen de España en la prensa internacional. En este conflicto, el gobierno mexicano tomó parte claramente por Madrid, cuando el secretario Videgaray anunció ante el Senado que México no reconocería una Cataluña independiente, ${ }^{55}$ siendo éste un asunto que generaba polémica en el país debido a la amplitud de vínculos sociales entre México y España. Esta misma diversidad de actores, más allá de los gobiernos centrales, permitió que se organizara una multiplicidad de eventos para celebrar los cuarenta años del restablecimiento de relaciones entre ambos países. ${ }^{56}$ Entre ellos destacó la apertura de la casa de México en Madrid, con una librería del Fondo de Cultura Económica, proyecto impulsado por la embajada de México en España, la alcaldía de Madrid y empresas privadas. ${ }^{57}$ Durante su última gira a Europa en abril de 2018, EPN visitó España y destacó

53 "Refrendan apoyo a Acuerdos de París", Reforma, 2 de noviembre de 2017.

${ }^{54}$ Javier Casqueiro, "España sólo brinda palabras de cariño a México frente a Trump", El País, 27 de enero de 2017.

${ }^{55}$ Secretaría de Relaciones Exteriores, SRE, "México no reconocerá a una Cataluña independiente", Comunicado de Prensa n. 379, 10 de octubre de 2017.

${ }^{56}$ Embajada de México en España, México-España, 40 aniversario, México, SRE, 2017.

${ }^{57}$ Lorena Ruano, "Entrevista con Roberta Lajous Vargas, embajadora de México en España”, Revista Mexicana de Política Exterior, 112 (2018), pp. 201-210. 
la "plena sintonía" entre ambos países al condenar al régimen de Maduro en Venezuela. En contraste, el asunto del nuevo aeropuerto internacional de la Ciudad de México inquietó a las empresas españolas que participaban en su construcción, ya que el candidato a la presidencia, Andrés Manuel López Obrador, anunció que la cancelaría. ${ }^{58}$

La relación con el RU, que se había venido cultivando al principio del sexenio, entró en "piloto automático", movida por inercias burocráticas y proyectos previstos anteriormente, pues la crisis interna en ese país con el asunto del Brexit absorbió prácticamente la totalidad de las capacidades del gobierno británico. Por su parte, la prensa británica, que en 2012 había anunciado el Mexico's Moment, cerraba la administración de EPN exhibiendo el estilo de vida en Londres de Karime Macías, esposa del exgobernador preso Javier Duarte, y expresando preocupación sobre la las señales enviadas por el presidente electo, López Obrador. ${ }^{59}$

Entretanto, se continuó con la diversificación de las relaciones con otros países del continente con las visitas a México de Lars Løkke, primer ministro de Dinamarca, del presidente de Polonia, Andrzej Duda, y del presidente de Portugal, Marcelo Rebelo de Sousa, en todos los casos con un fuerte tono de promoción económica. ${ }^{60}$ EPN también incluyó a los Países Bajos en su última gira por Europa (cuadro 1). La negociación con Rusia en torno a los visados, que se había detenido tras la condena a la anexión de Crimea en 2014, fue retomada por el canciller Videgaray de cara al mundial de futbol de 2018.

58 Javier Casqueiro, "Rajoy y Peña ratifican su «plena sintonía» contra Maduro", El País, 23 de abril de 2018.

59 Tom Phillips, "Mexico: wife of captured ex-governor living high life in London, rival alleges", The Guardian, 30 de mayo de 2018; "AMLO, Mexico's president elect, is sending worrying signals”, The Economist, 29 de noviembre de 2018.

${ }^{60}$ Francisco Reséndiz, "Van México y Portugal por mayor comercio", El Universal, 18 de julio de 2017. 
En el plano birregional, el panorama se volvió sombrío con la cancelación de la cumbre del Salvador UE-CELAC prevista para octubre de 2017, debido principalmente a los desacuerdos entre los miembros de la propia CELAC en torno a la crisis en Venezuela. Nadie parece extrañar el mecanismo ya cuestionado en la última cumbre de 2015 , y a principios de 2019 no está claro si se convocará una nueva reunión. Sin embargo, más allá de la relación birregional y de las cumbres, se observó una concordancia notable entre la posición de México y aquellas de la UE en favor de presionar al gobierno venezolano durante 2017, pues el primero lideró el Grupo de Lima en la Organización de Estados Americanos (OEA), mientras que la segunda impuso sanciones económicas al país caribeño. También hubo coincidencias en torno a la reactivación de las relaciones entre la UE y Cuba en 2017.

\section{Conclusión}

Al inicio del sexenio 2012-2018, los objetivos de la política exterior mexicana hacia Europa consistieron esencialmente en mejorar la imagen del país, en promover las reformas estructurales del Pacto por México para atraer inversión extranjera, fomentar mayor intercambio comercial y fortalecer las relaciones bilaterales más allá de Madrid y Bruselas, poniendo énfasis en las otras potencias como Francia, Alemania, RU, Italia y los países nórdicos. Con la UE se buscó la "modernización" del AG para no quedar fuera de la reorganización de las relaciones económicas que estaba negociándose entre la propia UE y América del Norte. Estos objetivos se cumplieron parcialmente debido a la continuidad en el diseño y ejecución de la política exterior. Sin embargo, algunos de los resultados, como la disrupción causada por el tema de derechos humanos o la aceleración de las negociaciones en 2017, se debieron en gran medida a cambios en el entorno internacional y nacional. 
En cuanto a la imagen en el exterior, la administración arrancó con una narrativa esperanzadora que tuvo eco gracias a las reformas estructurales, pero a partir de los sucesos de Ayotzinapa, a finales de 2015, la cruenta realidad mexicana se impuso. Las críticas de la prensa y las organizaciones de la sociedad civil se multiplicaron conforme saltaban al dominio público nuevos escándalos de corrupción, asesinatos de periodistas y fosas con cientos de cuerpos, mientras el gobierno mexicano adoptaba una posición cada vez más defensiva ante el escrutinio internacional. Si bien los gobiernos europeos y las autoridades comunitarias tuvieron que retomar estos incómodos llamados de atención, incluso al más alto nivel (Merkel, Mogherini, PE), mantuvieron una actitud "constructiva" de colaboración con el gobierno mexicano, ofreciendo apoyo y fondos para reforzar el Estado de derecho en México. No perdían de vista que, a pesar de todo, el gobierno mexicano seguía preconizando la defensa de los derechos humanos en el mundo y que compartía posturas similares en relación con otros muchos temas, desde Venezuela hasta el comercio libre basado en reglas.

En términos económicos, el frenazo de la economía mundial (2015-2016) con la caída de los precios del petróleo y otras commodities tuvo un efecto notorio, pues la inversión europea que se esperaba en México tuvo un pico entre 2013 y 2014, pero después retomó sus niveles históricos (gráficas 1 y 2). El comercio con la UE, por su parte, se estancó entre 2011 y 2017 (gráficas 3, 5 y 6) con años de franca caída entre 2015 y 2016, en contraste con el comercio total de México (gráfica 4) que sí creció entre 2011 y 2014, aunque también cayó en los años de crisis; la balanza comercial ha continuado con su tendencia deficitaria desde hace veinte años. En cuanto a la diversificación, el comercio y las inversiones han seguido concentrados en los mismos seis socios de siempre, Alemania y España en primer término, seguidos de Italia, RU, Francia y los Países Bajos, aunque ha aumentado la proporción de intercambios con 
el resto de la uE (de 19 a 24\% del total). En este ámbito, los esfuerzos de diversificación rindieron frutos.

El objetivo principal, la "modernización” del AG, tardó en lograrse. La UE, Estados Unidos y Canadá mantuvieron a México al margen de las negociaciones del CETA y TTIP, a pesar de que tendrían efectos sobre el país. No fue sino hasta el estancamiento del TTIP y la posterior llegada de Trump al poder, en la segunda mitad de 2016, que la ue mostró una voluntad clara de negociar con México e incluso de dar apoyo político frente a los embates del vecino. México negoció bajo la enorme presión que generaba la perspectiva de que desapareciera o se diluyera el TLCAN, y a contrarreloj con las elecciones de julio de 2018 encima. Se avanzó mucho, pero la negociación no está concluida, a pesar del "acuerdo en principio”. En el plano birregional, se pasó de querer encabezar una visión latinoamericana en un primer momento, a la toma de posición contra Venezuela hacia el final, conforme la relación UE-CELAC decaía, al punto de posponer sine die la cumbre de San Salvador 2017.

Las relaciones bilaterales mostraron un cambio sustantivo, en comparación con administraciones pasadas, en cuanto a la pérdida de protagonismo de la relación con España, frente a Francia, Alemania, el RU y otros países como Polonia, las naciones escandinavas, e incluso Turquía y Rusia. Ciertamente, la cancillería puso énfasis en esa diversificación, pero deben sumarse a esto las crisis internas que ha venido sufriendo España, y que contribuyeron a su relativo desdibujamiento dentro de la UE y en comparación con las potencias europeas. El avance con el RU, que se logró hasta 2016, se desvaneció tras el referéndum del Brexit, que sumió a ese país en una grave crisis política. Algo similar sucedió con Italia tras la caída del gobierno de Matteo Renzi en 2018. De este modo, lo que sí se consiguió fue el fortalecimiento de los vínculos con Francia y Alemania, Países Bajos y Escandinavia.

A pesar de que este sexenio se dividió en los tres periodos muy claros (y tres cancilleres), identificados al inicio de este artículo, se observó también continuidad en la política 
exterior hacia Europa, quizá relacionada con la permanencia del subsecretario Carlos de Icaza a lo largo de los seis años. Además, en los países más importantes estuvieron durante largo tiempo embajadores de peso y experiencia: Patricia Espinosa en Alemania (después vino Rogelio Granguillhome); Juan Manuel Gómez Robledo en Francia; Roberta Lajous en Madrid, y otros muchos funcionarios de carrera. Esta continuidad permitió que se dieran los logros en materia de cooperación cultural (exposiciones, Casa de México en Madrid, años duales) de alta visibilidad.

Quizá el logro más importante del sexenio haya sido la "modernización" del AG con la UE, y ello se debió, en gran medida, a la coyuntura internacional más que a la estrategia mexicana. Es crucial que esta negociación concluya con éxito en los meses por venir para apuntalar la diversificación política y económica del país, que se ha vuelto urgente en estos días. El mayor desafío sin duda fue el asunto de los derechos humanos y las carencias del Estado de derecho en México. En esta materia, sin embargo, la ue dejó de actuar con la solidez y la coherencia que la caracterizaron en el pasado reciente, debido a la erosión del consenso entre los Estados miembros. Hubo enorme variación de posturas hacia México: algunos fueron críticos (Escandinavia, Alemania, $\mathrm{RU}$ ), otros, para los que predominaron intereses económicos o políticos, lo fueron menos (España, Francia) y otros se han alejado del consenso comunitario de antaño (Polonia, Hungría). A pesar de este cambio, en Europa siguen estando el grupo de socios de México que más énfasis pone en el tema. 


\section{Cuadro 1 \\ Giras presidenciales de Enrique Peña Nieto a Europa (2012-2018)}

\begin{tabular}{|c|c|c|}
\hline Fechas & Países & Motivo de la gira \\
\hline 10-18 de octubre de 2012 & $\begin{array}{l}\text { Alemania, España, Reino } \\
\text { Unido y Francia }\end{array}$ & $\begin{array}{l}\text { Gira de trabajo (como presidente } \\
\text { electo) }\end{array}$ \\
\hline 18-21 de marzo de 2013 & Santa Sede & $\begin{array}{l}\text { Ceremonia de inicio de pontificado } \\
\text { del Papa Francisco }\end{array}$ \\
\hline 15-21 de diciembre de 2013 & Turquía & $\begin{array}{l}\text { Firma de un acuerdo de asociación } \\
\text { estratégica }\end{array}$ \\
\hline 21-23 de enero de 2014 & Suiza & Foro Económico Mundial de Davos \\
\hline 5-10 de junio de 2014 & $\begin{array}{l}\text { Portugal, España y la } \\
\text { Santa Sede }\end{array}$ & $\begin{array}{l}\text { Profundizar vínculos con socios } \\
\text { estratégicos }\end{array}$ \\
\hline 2-5 de marzo de 2015 & Reino Unido & $\begin{array}{l}\text { Establecer el Grupo de Alto Nivel } \\
\text { México-Reino Unido } \\
\text { Celebración del Año Dual México- } \\
\text { Reino Unido }\end{array}$ \\
\hline 9-16 de junio de 2015 & Bélgica e Italia & $\begin{array}{l}\text { II Cumbre UE-CELAC, VII Cumbre } \\
\text { México- UE y Expo Milán } 2015\end{array}$ \\
\hline 13-16 de junio de 2015 & Francia & $\begin{array}{l}\text { Celebración del Día Nacional de } \\
\text { Francia }\end{array}$ \\
\hline $15-16$ de noviembre de 2015 & Turquía & Cumbre de Líderes del G20 \\
\hline 22-23 de enero de 2016 & Suiza & Foro Económico Mundial de Davos \\
\hline 10-14 de abril de 2016 & Alemania y Dinamarca & Gira oficial \\
\hline 6-8 de julio de 2017 & Francia y Alemania & $\begin{array}{l}\text { Visita oficial y Cumbre de Líderes } \\
\text { del G20 }\end{array}$ \\
\hline 10-12 de diciembre de 2017 & Francia & Cumbre One Planet \\
\hline 22-25 de abril de 2018 & $\begin{array}{l}\text { Alemania, Países Bajos y } \\
\text { España }\end{array}$ & Gira oficial \\
\hline
\end{tabular}

Fuente: Secretaría de Relaciones Exteriores, Informes de labores 2012-2018. 


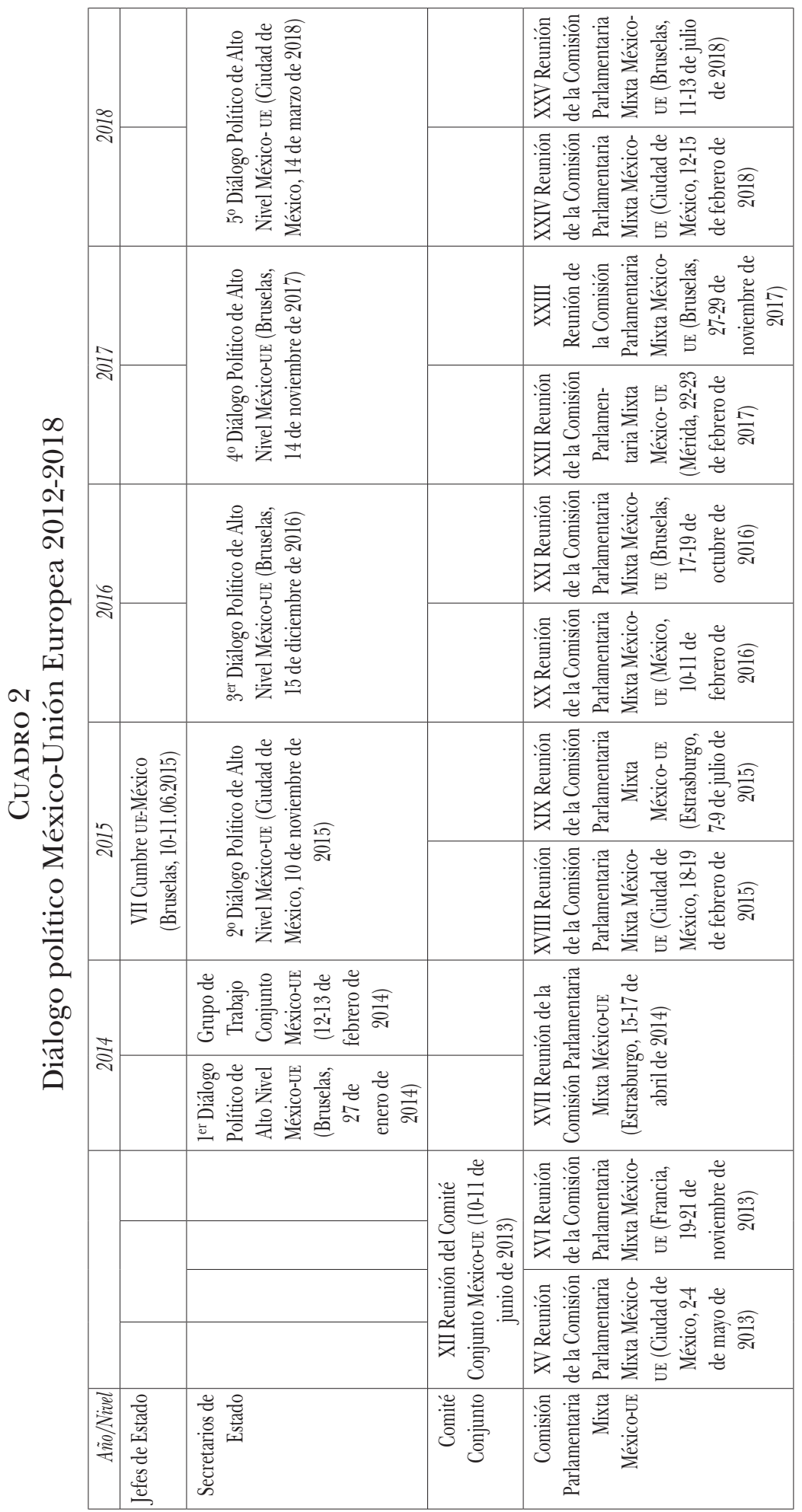




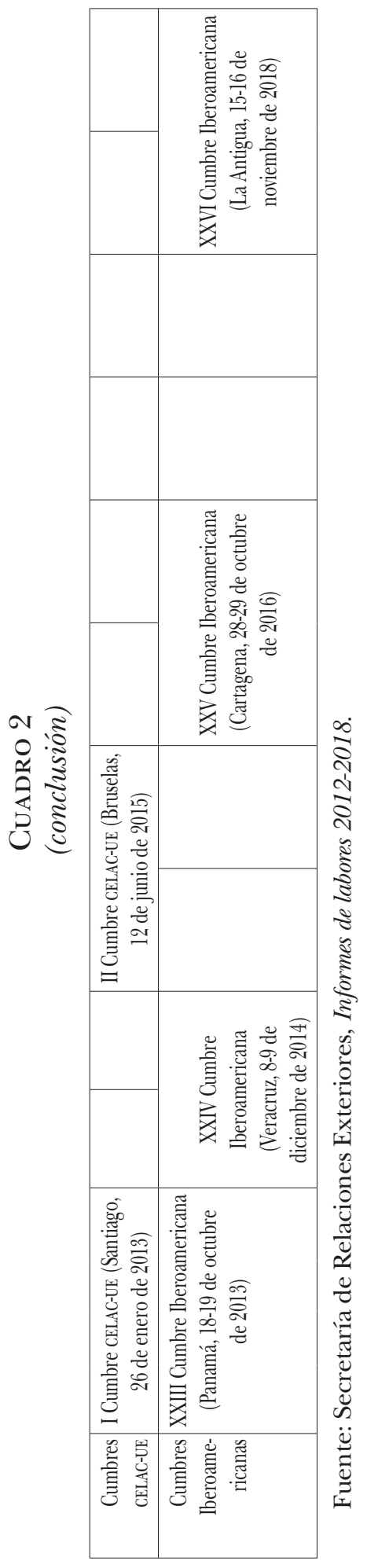




\section{GráFICA 1}

Distribución de la inversión extranjera directa proveniente de los principales socios económicos, 2000-2017

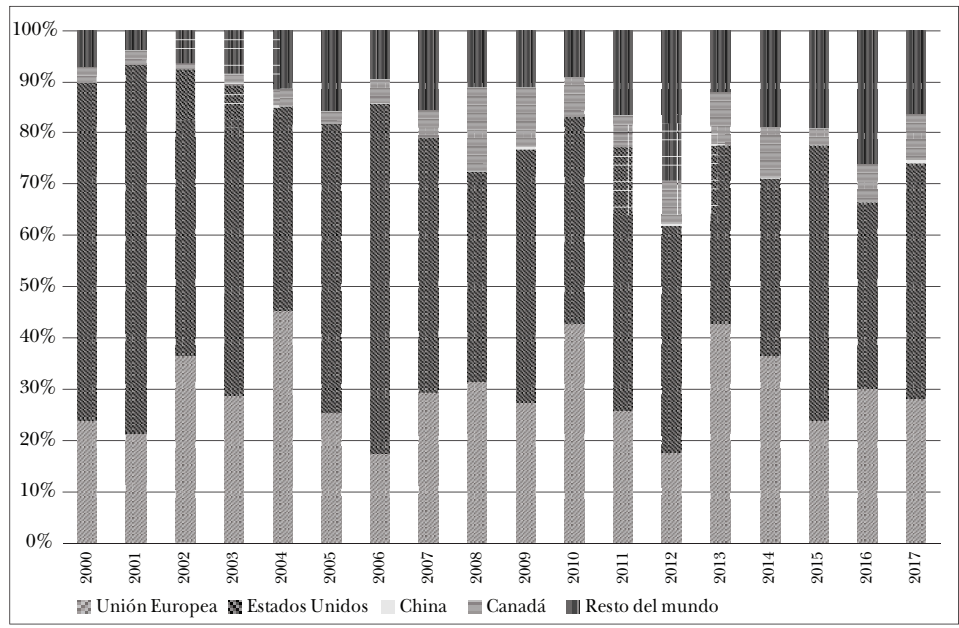

GRÁFICA 2

Inversión extranjera directa en México proveniente de países de la Unión Europea, 2000-2017

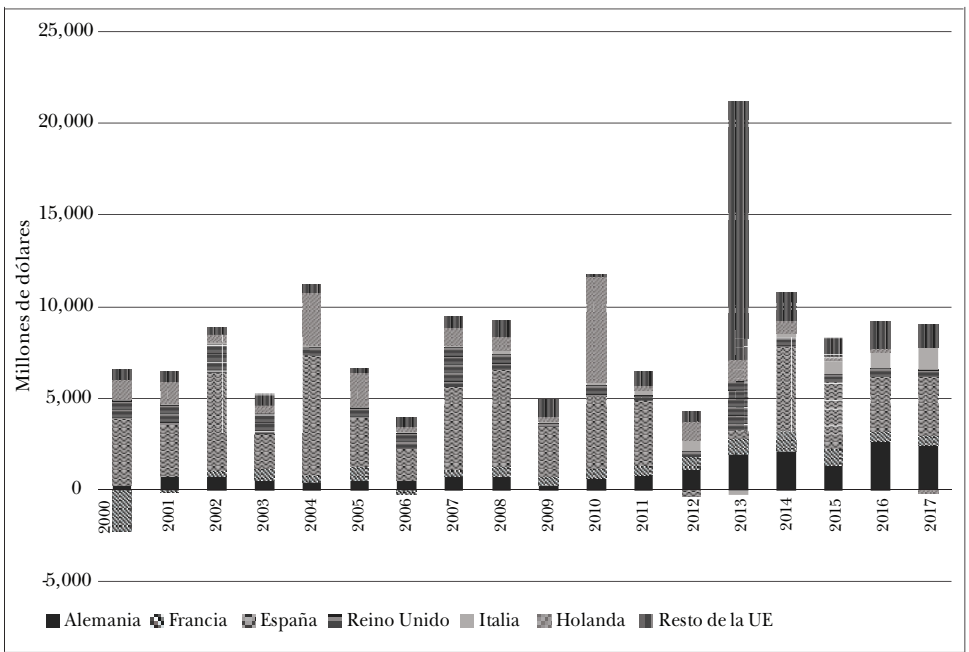


Gráfica 3

Comercio total de México con sus principales socios en la Unión Europea 2000-2018

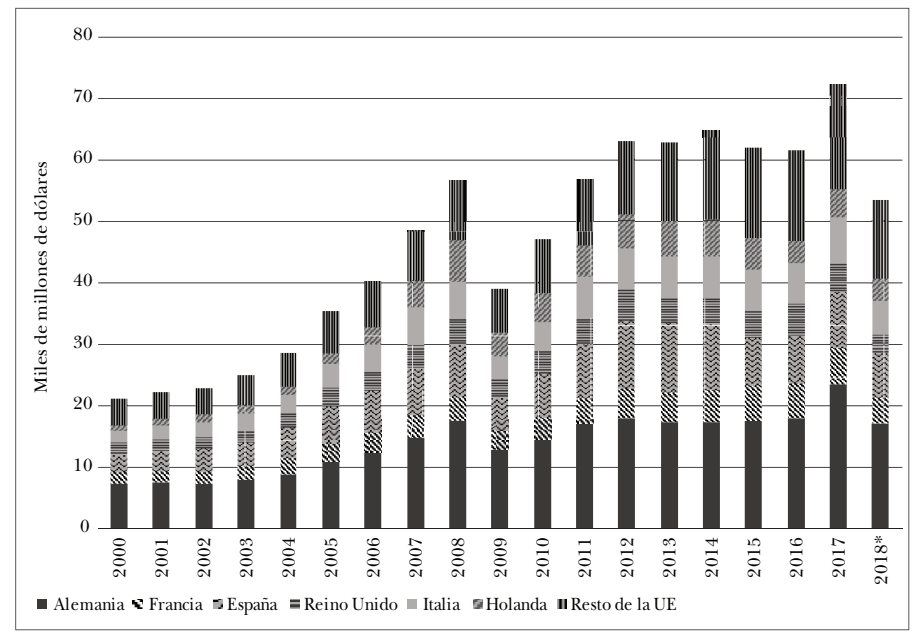

GRÁFICA 4

Comercio total entre México y sus principales socios comerciales 2000-2018

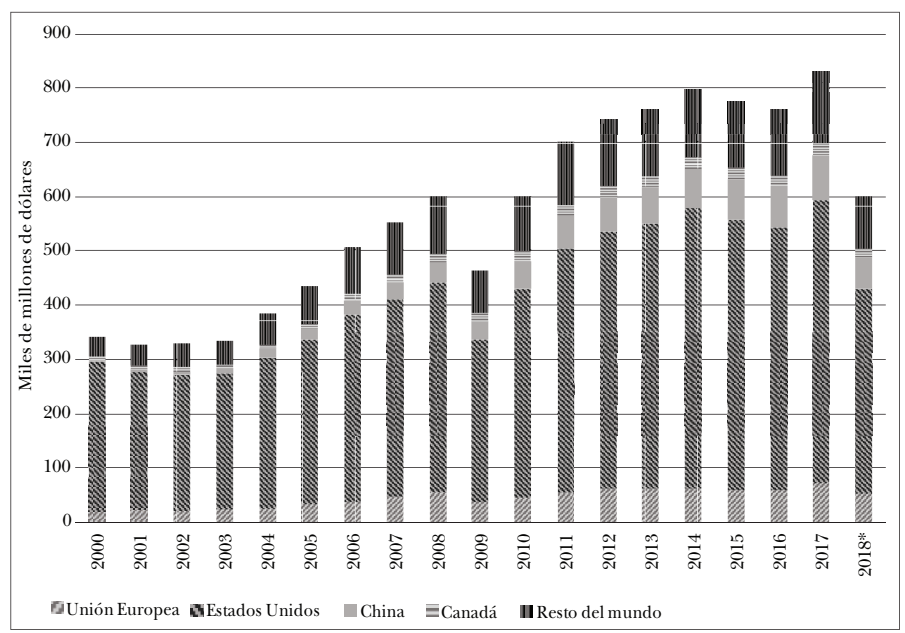

Fuente: elaboración propia con datos del INEGI.

* Datos hasta agosto de 2018. 


\section{GráfICA 5}

Gráfica 5. Exportaciones de México a países de la Unión Europea 2000-2018

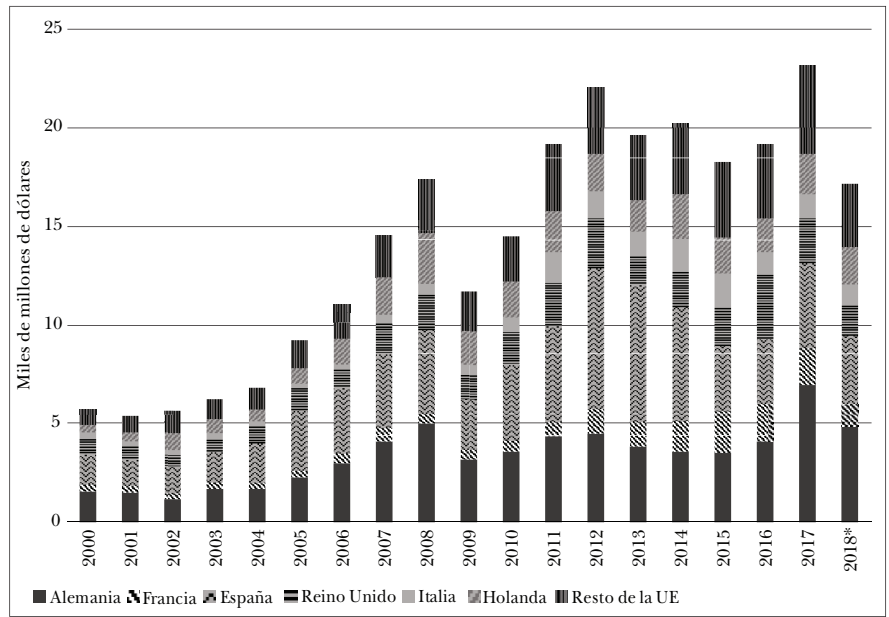

\section{GrÁfICA 6}

Importaciones mexicanas de países de la Unión Europea 2000-2018

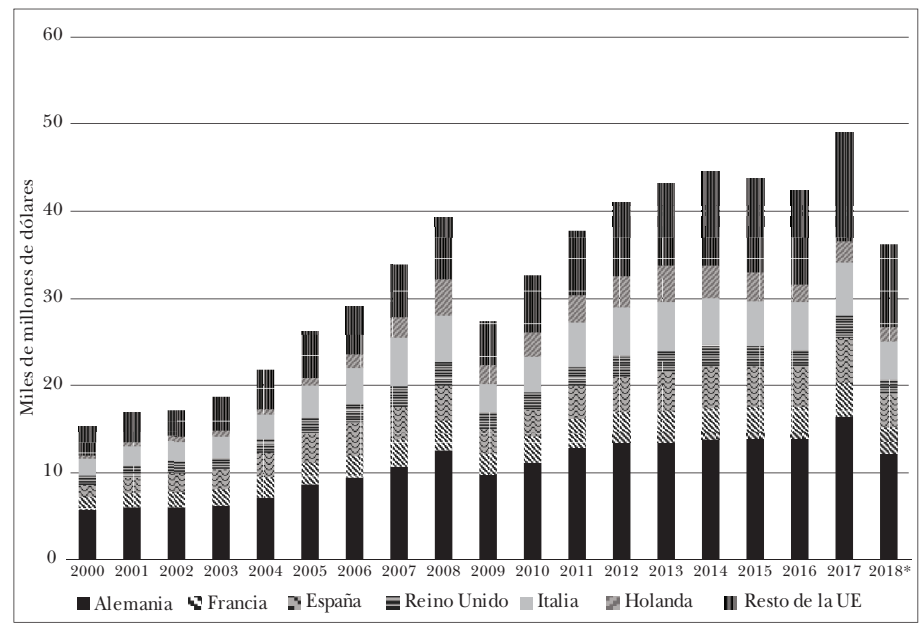

Fuente: elaboración propia con datos del INEGI.

* Datos hasta agosto de 2018. 


\section{FUENTES Y BIBLIOGRAFÍA}

\section{Entrevista citada}

Entrevista con alto funcionario del SEAE, Bruselas, 7 de febrero de 2017.

\section{Hemerografía}

"Activistas franceses protestan en el Consejo de París contra la visita de Peña Nieto en Francia”, Sin embargo, 2 de julio de 2015, https://www.sinembargo.mx/02-07-2015/1400095 (consulta del 27 de noviembre de 2018).

“AMLO, Mexico's president elect, is sending worrying signals", The Economist, 29 de noviembre de 2018.

"Angela Merkel condemns «putting up walls» during Mexico visit", The Guardian, 10 de junio de 2017.

"Angela Merkel: The new leader of the Free World", Politico Magazine, enero de 2017, en www.politico.com/interactives/2017/politico50/angela-merkel (consulta del 3 de diciembre de 2018).

"Así funcionará el nuevo trámite para ingresar a los países de Europa del espacio Schengen", BBC News Mundo, 17 de noviembre de 2016, https://www.bbc.com/mundo/noticias-america-latina-38015758 (consulta del 27 de noviembre de 2018).

Beauregard, Luis Pablo, "Francia y México buscan el deshielo de sus relaciones tras el «affaire» Cassez", El País, 9 de abril de 2014.

Becerril, Andrea, "El mundo espera más de México: Sarkozy", La Jornada, 10 de marzo de 2009.

"Beneplácito del presidente electo mexicano al acuerdo con los astilleros españoles", El País, 13 de octubre de 2012.

Bugarin, Inder, "Eurodiputados apoyan a México contra Trump", El Universal, 27 de enero de 2017.

BugARIN, Inder, "Europa, inquieta por protestas", El Universal, 10 de enero de 2017.

Casqueiro, Javier, "España sólo brinda palabras de cariño a México frente a Trump”, El País, 27 de enero de 2017. 
Casqueiro, Javier, "Rajoy y Peña ratifican su «plena sintonía» contra Maduro", El País, 23 de abril de 2018.

"Cemex compra activos de Holcim en Europa", El Universal, 6 de enero de 2015.

"El comisario de comercio de la ue fortalecerá lazos comerciales en México y Perú”, La Información, 9 de noviembre de 2012.

"El líder del Parlamento Europeo percibe apertura a inversiones en Pemex", investing.com, 12 de febrero de 2013, https://mx. investing.com/news / commodities-news / el-lider-del-parla mento-europeo-percibe-apertura-a-inversiones-en-pemex-9088

"El príncipe Felipe llama a las empresas mexicanas a invertir en España”, El País, 30 de noviembre de 2012.

"Fidel Herrera renuncia a consulado de México en Barcelona", $E l$ Universal, 22 de enero de 2017.

"France-Mexique: entre Paris et Mexico, un partenariat stratégique sur les rails", Le Moci, 6 de noviembre de 2017.

García, Ariadna, "Videgaray pide a diplomáticos impulsar a México en Europa", El Universal, 19 de febrero de 2017.

"Germany issues travel advisory for Mexico due to expected violence in the run up to the elections", El Universal [en inglés], 27 de febrero de 2018.

"Germany's Merkel talks trade and human rights in Mexico", Daily Mail, 9 de junio de 2017.

GonzÁlez, Miguel, "Francia e Italia toman la delantera a España en América Latina”, El País, 9 de febrero de 2016.

GonzÁlez, Miguel, "Los Reyes viajan a México para su segunda visita de Estado", El País, 27 de julio de 2015.

Irujo, José María, "Misión: salvar en Madrid a Humberto Moreira", El País, 22 de febrero de 2016.

"Merkel: Europe «can no longer rely on allies» after Trump and Brexit”, BBC News, 28 de mayo de 2017, https:/ /www.bbc.com/ news/world-europe-40078183 (consulta del 30 de noviembre de 2018).

"Mexico human rights: Cameron to raise issue with Pena Nieto", $B B C$ News, 4 de marzo de 2015, https://www.bbc.com/news/ uk-31723447 (consulta del 27 de noviembre de 2018). 
"México invirtió más de 35 mmdd en Europa”, Excélsior, 27 de diciembre de 2014.

"México lamenta actos de violencia y muertes en Ucrania", El Universal, 19 de febrero de 2014.

"Mexico's Moment", The Economist, 24 de noviembre de 2012.

Müller, Enrique, "La violencia empaña brillo de México en la Feria Internacional de Turismo de Berlín”, El País, 25 de febrero de 2014.

"Peña Nieto ofrece ayuda a España para salir de la crisis", El Universal, 15 de octubre de 2012.

"Peña Nieto parte a Europa para gira de trabajo", Notimex, 5 de julio de 2017.

Phillips, Tom, "Mexico: wife of captured ex-governor living high life in London, rival alleges", The Guardian, 30 de mayo de 2018.

"Pide ue apertura a inversión", Reforma, 2 de mayo de 2002.

Quesada, Juan Diego, "México y Francia invertirán hasta 500 millones en la industria aeroespacial”, El País, 15 de julio de 2013.

"Recibe rey Juan Carlos a Peña Nieto", El Universal, 15 de octubre de 2012.

"Refrendan apoyo a Acuerdos de París", Reforma, 2 de noviembre de 2017.

ReinA, Elena, "El trágico final de dos ciclistas europeos asesinados en Chiapas", El País, 12 de mayo de 2018.

"Reino Unido abre la puerta a México a un TLC tras el Brexit", $E l$ Financiero, 5 de septiembre de 2016.

Reséndiz, Francisco, "Van México y Portugal por mayor comercio", El Universal, 18 de julio de 2017.

Rodríguez García, Arturo, "Diplomacia pendenciera y vilipendiada", Proceso, 19 de abril de 2016.

"Saving Mexico: How Enrique Peña Nieto's sweeping reforms have changed the narrative in his narco-stained nation", Time, $24 \mathrm{de}$ febrero de 2014.

VArgas, Rosa Elvira, "Peña Nieto llegó ayer a Alemania; se reúne hoy con Merkel", La Jornada, 11 de octubre de 2012.

Villa y CaÑa, Pedro, "Movilización por los 43 tiene eco internacional", El Universal, 27 de febrero de 2015. 
Villa y Caña, Pedro, "Regresan protestas a ciudades de América y Europa”, El Universal, 23 de octubre de 2014.

\section{Publicaciones oficiales}

\section{De la Unión Europea}

European Commission (EC), Trade for All - Towards a more responsible trade and investment policy, Bruselas, EC, 2015.

European Commission, Commission Staff Working Document. Impact Assessment accompanying the document Recommendation for a Council Decision authorising the European Commission and the High Representative of the Union for Foreign Affairs and Security Policy to open negotiations and to negotiate with Mexico a modernised Global Agreement, SWD (2015) 289 final, Bruselas, 16 de diciembre de 2015.

Delegación de la Unión Europea en México, “Alta Representante de la ue para Asuntos Exteriores y de Seguridad/Vicepresidenta, Federica Mogherini visita México el 24 y 25 de mayo", Comunicado de prensa, 23 de mayo de 2016.

Parlamento Europeo (PE), "Declaración de la portavoz sobre el informe final del GIEI acerca de la investigación sobre la desaparición de los 43 estudiantes en Iguala (México)”, 2014/2905 (RSP).

Servicio Europeo de Acción Externa (SEAE), Comunicado de prensa 161107_10, Bruselas, 29 de abril de 2016.

"EU Trade Commissioner in Mexico: «Trade deal possible by year's end»", 8 de mayo de 2017, http:/ / trade.ec.europa.eu/doclib/ press/index.cfm?id=1659 (consulta del 30 de noviembre de 2018).

“'United we stand, divided we fall', Letter by President Donald Tusk to the $27 \mathrm{EU}$ heads of state or government on the future of the EU before the Malta Summit", 31 de enero de 2017, www.consi lium.europa.eu/en/press/press-releases/2017/01/31-tusk-let ter-future-europe/ (consulta del 30 de noviembre de 2018). 
"New EU-Mexico Agreement: The Agreement in Principle", Bruselas, 23 de abril de 2018, http://trade.ec.europa.eu/doclib/ docs/2018/april/tradoc_156791.pdf (consulta del 20 de junio de 2018).

European Union, European Press Releases (RAPID), 2012-2018.

\section{De México}

Embajada de México en España, México-España, 40 aniversario, México, SRE, 2017.

Secretaría de Relaciones Exteriores, SRE, "México manifiesta su profunda preocupación por el deterioro de la situación en Ucrania", Comunicado de prensa, 4 de marzo de 2014.

Secretaría de Relaciones Exteriores, SRE, "México no reconocerá a una Cataluña independiente", Comunicado de prensa núm. 379, 10 de octubre de 2017.

Secretaría de Relaciones Exteriores, SRE, Informes de labores, 20122018, México.

Secretaría de Economía, www.se.gob.mx

\section{Otras}

VII EU-Mexico Summit, Joint Statement, Bruselas, 12 de junio de 2015.

CELAC-EU, Assessment of Programmes and Actions, Santo Domingo, 2016, http://www.consilium.europa.eu/media/24235/readthe-assessment-of-programmes-and-actions.pdf (consulta del 28 de noviembre de 2018).

EU-CELAC Brussels Summit 2015, EU-CELAC Action Plan, Bruselas, 10-11 de junio de 2015.

Political Declaration of EU-CELAC Heads of State and Government, Bruselas, 10-11 de junio de 2015.

"Mexico: Joint statement of NGOs in the European Union (EU) on the publication of the final GIEI Report”, Coordinación Alemana por los Derechos Humanos en México, 17 de mayo de 2016, https:/ / esp.mexiko-koordination.de/40-tagung-2012/1 25-mexico-joint-statement-of-ngos-in-the-european-union-eu- 
on-the-publication-of-the-final-giei-report.html (consulta del 28 de noviembre de 2018).

\section{Fuentes secundarias}

De IcAzA, Carlos, "México y Europa: una historia de amistad, solidaridad y cooperación”, Revista Mexicana de Política Exterior, 112 (2018), pp. 17-32;

Del Río, Francisco y Raúl SaAvedra Cinta, "Modernización de los capítulos de diálogo político y de cooperación del Acuerdo Global México-Unión Europea”, Revista Mexicana de Política Exterior, 112 (2018), pp. 33-48.

Granguillhome Morfín, Rogelio, y Víctor Manuel Jiménez SeGOVIA, "Las relaciones con Alemania y cómo fortalecer la presencia de México en el mundo de hoy", Revista Mexicana de Política Exterior, 112 (2018), pp. 109-128.

MAinold, Günther, "Migración, control de fronteras y acuerdos migratorios con terceros países”, Revista Mexicana de Política Exterior, 112 (2018), pp. 161-183.

RuAno, Lorena, "Entrevista con Roberta Lajous Vargas, embajadora de México en España”, Revista Mexicana de Política Exterior, 112 (2018), pp. 201-210.

RuAno, Lorena, "The "Modernisation" of the Global Agreement between Mexico and the EU" en Antonella Mori, (ed.), EU and Latin America and the Caribbean: A Stronger Partnership?, Roma, ISPI, 2018, pp. 47-66. 
